\title{
PLoS Medicine and the Pharmaceutical Industry
}

The PLoS Medicine Editors

I n PLoS Medicine's launch issue in 2004, we declared that we would not be part of "the cycle of dependency that has formed between journals and the pharmaceutical industry" (DOI: 10.1371/journal.pmed.0010022). We set out three policies aimed at breaking this cycle. First, we would not publish adverts for drugs and devices. Second, we would not benefit from exclusive reprint sales to drug companies, since our open access license would let readers make unlimited copies themselves. Third, we would decline to publish studies aimed purely at increasing a drug's market share.

We adopted these policies out of a concern that medical journals have allowed their interests to become too closely aligned with those of the marketing departments of drug companies. The public response to our position has, for the most part, been very positive-PLoS Medicine was even cited as a "hopeful example" of how the medical profession can disentangle from industry (Lancet 367: 202).

And in a recent policy paper in PLoS Medicine, Fugh-Berman and colleagues argued that other medical journals should follow our example and ban adverts for drugs and devices (DOI: 10.1371/journal.pmed.0030130).

The idea of such a ban has, not surprisingly, angered some representatives of the pharmaceutical industry, which gets a return of investment of US\$5 for every dollar it spends on advertising to doctors (http://www.rxpromoroi.org/rapp/ index.html). John Kamp, executive director of the Coalition for Healthcare Communication, a group of advertising agencies and public relations firms representing the pharmaceutical industry, called Fugh-Berman and colleagues' suggestion a "goofy idea" (MMM 23 June 2006). He also said that "PLoS Medicine needs to take a basic course in the First Amendment [the right of free speech in the US Constitution]."

Drug companies regularly cry "free speech" whenever anyone suggests that their promotional efforts should be curtailed. Billy Tauzin, president of the Pharmaceutical Research Manufacturers of America, went so far as to suggest that such curtailment would be a "human rights abuse" (www.mediaweek.com/mw/search/ article_display.jsp?vnu_content_ $\mathrm{id}=1001002068$ ). This is nonsense. Drug advertising is often misleading (Ann Intern Med 116: 912-919), and it can potentially distort clinical practice (Circulation 99: 2055-2057). The need to prevent another Vioxx tragedy, in which the "drug marketing got well ahead of the science" (DOI: 10.1371/journal.pmed.0030145),

\section{"Journals have got to distinguish between science and marketing."}

requires us all to think carefully about the net effect upon society of drug adverts. Public health must always come before industry's unfettered "rights." Our recent theme issue on disease mongering (http://collections.plos. org/diseasemongering-2006.php) has provoked what we believe is a useful debate about when marketing comes before science.

Alongside the growing public scrutiny of drug advertising in journals, there is also increasing questioning of the way in which journals own the copyright on research articles and then make huge profits by exclusively selling reprints to industry. Such profits have the potential to influence editorial decisions, and our second policy is thus aimed at minimizing this potential conflict of interest. A recent investigative report in The Wall Street Journal (May 15th), which examined "the New England Journal's role in the Vioxx debacle," gave an indication of the sums of money that change hands between journals and drug companies in this exclusive reprint trade. The New England Journal of Medicine sold 929,400 reprints of the "Vioxx trial," more than one for every doctor in the US, mostly to Merck (the manufacturer of Vioxx), bringing in between US\$697,000 and US $\$ 836,000$ for the Journal.
No one questions, however, that industry has great expertise in clinical research. It has funded many of the trials that led to the greatest medical breakthroughs (such as the ISIS-II study [Lancet 2: 349-360]), and it holds the keys to the development of many more lifesaving interventions, including those aimed at the most neglected diseases (DOI: 10.1371/ journal.pmed.0020302). Why then did we adopt the third of our policies? Our aim was to ensure that we publish only those industry-funded studies that have important public health implications, such as those showing under-use of aspirin (DOI: 10.1371/ journal.pmed.0020353) and statins (DOI: 10.1371/journal.pmed.0020123) for the prevention of cardiovascular disease. However, "some studies funded by industry have been more helpful to marketing than to advancing clinical care," said Patrick Vallance, PLoS Medicine editorial board member, in his testimony to the UK House of Commons Health Committee enquiry on the pharmaceutical industry. In an interview with PLoS Medicine, Vallance said that journals have "got to distinguish between science and marketing." He also said that journal editors must surely base their decisions about whether to publish a study on its quality and not on its funding source.

Vallance recently left academia to head drug discovery at GlaxoSmithKline and we debated whether it would represent too much of a conflict to have an "industry insider" in the journal's ranks. Our decision to keep him on our editorial board (recognizing his expertise and experience) signals our continuing

Citation: The PLoS Medicine Editors (2006) PLOS Medicine and the pharmaceutical industry. PLoS Med 3(7): e329. DOI: 10.1371/journal.pmed.0030329

DOI: 10.1371/journal.pmed.0030329

Copyright: $\odot 2006$ The PLoS Medicine Editors. This is an open-access article distributed under the terms of the Creative Commons Attribution License, which permits unrestricted use, distribution, and reproduction in any medium, provided the original author and source are credited.

E-mail: medicine_editors@plos.org 
interest to work constructively, but not unquestioningly, with the pharmaceutical industry, within the policies of our journal.

So although we have attracted criticism (The Times' science correspondent Mark Henderson, for example, said that the "outright cynicism" shown by the disease mongering theme issue towards drug companies can "blind us to the benefits" that their products can bring [15 April 2005]), we would argue that stimulating debate on all issues relating to health is one of the jobs of a medical journal. A medical journal that accepts without question any one position serves society's needs very poorly.

Vallance has spoken about the steps that doctors and drug companies must both take to ensure a more professional, less-conflicted interaction and about the huge benefits to society when academia and industry work collaboratively. "Interaction between academic clinicians and industry," he told the House of Commons, "should be open, transparent and appropriately recognized by both sides." We agree, and would extend this to saying that academic medical journals and industry should adopt a similarly "open and transparent” relationship.

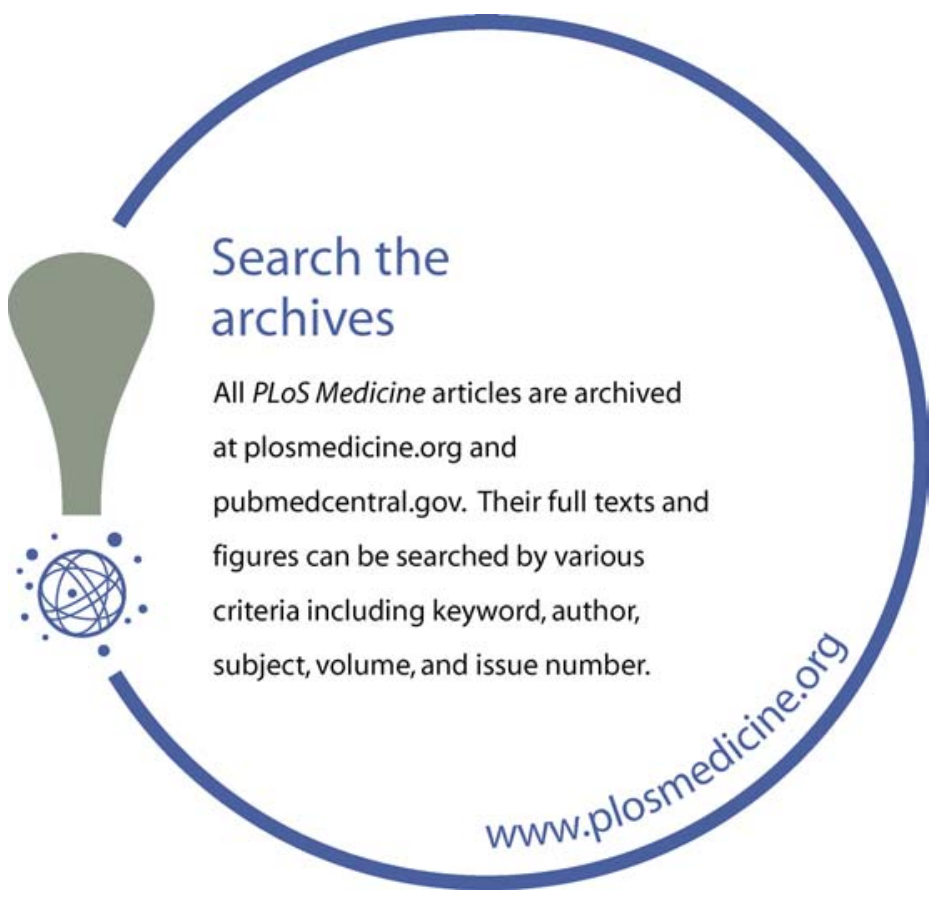

